\title{
Variedades de feijão-fava submetidas à níveis de salinidade e adubação orgânica
}

Mateus Batista Granja ${ }^{1}$, Plínio José Patriota Vitorino ${ }^{1}$, Valéria Fernandes de Oliveira Sousa ${ }^{1}$, Marília Hortência Batista Silva Rodrigues ${ }^{1}$, Genilson Lima Diniz ${ }^{1}$, Francisco Hélio Alves de Andrade ${ }^{2}$, Reginaldo Gomes Nobre ${ }^{1}$

${ }^{1}$ Universidade Federal de Campina Grande - UFCG. ${ }^{2}$ Universidade Federal de Lavras - UFLA, Lavras, MG. E-mail: mateussgranja@gmail.com

\section{Resumo}

As altas temperaturas e baixa pluviosidade salinizam água e solo na Região Nordeste, ocasionando redução no desenvolvimento de diversas espécies, dentre elas, o feijoeiro fava. Para tanto, objetivou-se avaliar variedades de feijão-fava submetidas a níveis de salinidade e adubação orgânica. $O$ estudo foi conduzido em ambiente protegido, nas dependências da Universidade Federal de Campina Grande, campus Pombal. 0 delineamento experimental foi em blocos ao acaso, disposto em esquema fatorial $3 \times 4 \times 5$, sendo: três variedades de feijão-fava (V1: lavandeira; V2: raio-de-sol e V3: rajada), quatro volumes de esterco bovino (A1: 0\% - sem adubação; A2: 8\%; A3: 16\% e A4: 24\%), aplicados em função do volume de solo do recipiente e cinco níveis de salinidade na água de irrigação $\left(\mathrm{S}_{1}=0,3 \mathrm{dSm}^{-1} ; \mathrm{S}_{2}=1,0 \mathrm{dSm}^{-1} ; \mathrm{S}_{3}=1,7 \mathrm{dSm}^{-1} ; \mathrm{S}_{4}=2,4 \mathrm{dSm}^{-1} \mathrm{e}\right.$ $\left.\mathrm{S}_{5}=3,1 \mathrm{dSm}^{-1}\right)$. A variedade Raio de Sol apresentou maior crescimento em relação às demais, entretanto a cultivar Rajada apresentou maior aclimatização às condições salinas, principalmente com uso do esterco bovino na concentração de $24 \%$. O esterco bovino atenua o efeito nocivo da salinidade, entretanto doses acima de $16 \%$ de esterco em altas salinidades podem ser prejudiciais ao feijoeiro-fava.

Palavras-chave: água salina; comportamento vegetativo; manejo orgânico; esterco; Phaseolus lunatus L.

\section{Varieties of bean-fava submitted to levels of salinity and organic fertilizing}

\begin{abstract}
The high temperatures and low rainfall salinize water and soil in the Northeast Region, causing a reduction in the development of several species, among them, fava bean. The objective of this study was to evaluate bean-fava varieties submitted to levels of salinity and organic fertilization. The study was conducted in a protected environment, in the dependencies of the Federal University of Campina Grande, Pombal campus. The experimental design was a randomized block design, arranged in a $3 \times 4 \times 5$ factorial scheme: three varieties of bean (V1: lavandeira, V2: sunshine and V3: rajada), four volumes of bovine manure (A1: $0 \%$ without fertilization; A2: $8 \%$; A3: $16 \%$ and A4: $24 \%$ ), applied as a function of the soil volume of the container and five levels of salinity in the irrigation water $\left(\mathrm{S} 1=0.3 \mathrm{dSm}^{-1} ; \mathrm{S} 2=1.0 \mathrm{dSm}^{-1} ; \mathrm{S} 3=1.7 \mathrm{dSm}^{-1} ; \mathrm{S} 4\right.$ $=2.4 \mathrm{dSm}^{-1}$ and $\mathrm{S} 5=3.1 \mathrm{dSm}^{-1}$ ). The Raio de Sol variety presented higher growth in relation to the others, however, the cultivar Rajada presented a higher acclimatization to saline conditions, mainly with the use of bovine manure in the concentration of $24 \%$. Bovine manure attenuates the harmful effect of salinity, however, doses above $16 \%$ of manure at high salinity can be harmful to common bean.
\end{abstract}

Keywords: saline water; vegetative behavior; organic management; manure; Phaseolus lunatus L.

\section{Introdução}

O feijão-fava (Phaseolus lunatus L.) é uma importante fonte alternativa de alimentação e renda para as populações mais carentes na região Nordeste do Brasil, devido a adaptabilidade ao clima semiárido, sendo seu cultivo realizado por pequenos produtores os quais se utilizam predominantemente de variedades crioulas de crescimento indeterminado (CARMO et al., 2015). A Paraíba é o principal produtor brasileiro de 
feijão-fava, com área plantada de 8.254 ha, produção de $1.439 \mathrm{t}$, e produtividade de $200 \mathrm{~kg}$ $\mathrm{ha}^{-1} / \mathrm{ano}$, corresponde a $35,8 \%$ da produção nacional, conforme dados do IBGE (2016).

A salinidade da água é um fator limitante ao desenvolvimento do feijão-fava, sendo esse estresse abiótico comum em regiões áridas e semiáridas, diminuindo o crescimento e produtividade de diversas espécies (NASCIMENTO et al., 2017; DINIZ et al., 2018). O uso de água salina resulta em efeitos negativos sobre o desenvolvimento fenológico e rendimento produtivo, em razão de que restringe o transporte de água para as plantas, provocando desequilíbrio nutricional e toxicidade de íons específicos (TERCEIRO NETO et al., 2013; TAIZ et al., 2017). Contudo, a tolerância salina diverge entre espécies e cultivares ou variedades de uma mesma espécie (SOUSA, 2017).

Além disso, algumas medidas de tratos culturais podem atenuar esse efeito deletério da salinidade, como a utilização de insumos orgânicos, dentre eles, o esterco bovino que proporciona incremento do crescimento vegetal, pois promove aumento da absorção e eficiência do uso da água pelas plantas, o que consequentemente resulta em maior absorção de nutrientes e maior expansão e divisão celular (NASCIMENTO et al., 2016). Diversas espécies demonstraram atenuação com uso do esterco bovino em condições salinas, dentre elas, algodoeiro (SOUZA et al., 2018), melancieira (SILVA JÚNIOR et al., 2017) e maracujazeiro (NUNES et al., 2017).

Devido a falta de estudos relacionados aos tratos culturais, adubação orgânica com esterco, para o feijão-fava e a indisponibilidade de água de boa qualidade, assim como, a necessidade de selecionar cultivares resistentes à salinidade, objetivou-se avaliar o comportamento de variedades de feijão fava submetidas a níveis de salinidade na água de irrigação e adubação orgânica.

\section{Material e Métodos}

O experimento foi conduzido no período de dezembro de 2017 à março de 2018 nas dependências da Universidade Federal de Campina Grande, no Centro de Ciências e Tecnologia Agroalimentar (CCTA), Pombal, Paraíba, localizado geograficamente na latitude 060 46' 13" S e longitude 370 48' 06" W, com altitude de 184 metros acima do nível do mar. O clima do município, segundo a classificação de Koppen, é do tipo Bsh, que representa clima quente e seco com chuvas de verão/outono (ALVARES et al., 2013).

$O$ delineamento experimental foi em blocos casualizados com esquema fatorial $5 \times 3 \times 4$ constituído de cinco níveis de salinidade aplicados por meio da irrigação diária $\left(\mathrm{S}_{1}=0,3\right.$ $\mathrm{dSm}^{-1} ; \mathrm{S}_{2}=1,0 \mathrm{dSm}^{-1} ; \mathrm{S}_{3}=1,7 \mathrm{dSm}^{-1} ; \mathrm{S}_{4}=2,4 \mathrm{dSm}^{-1}$ e $S_{5}=3,1 \mathrm{dSm}^{-1}$ ) utilizando como soluto o cloreto de sódio $(\mathrm{NaCl})$, três variedades de feijão-fava $\left(\mathrm{V}_{1}\right.$ : lavandeira; $\mathrm{V}_{2}$ : raio-de-sol e $\mathrm{V}_{3}$ : rajada), adubadas com quatro volumes de esterco bovino $\left(A_{1}: 0 \%\right.$ (sem adubação); $A_{2}: 8 \% ; A_{3}: 16 \%$ e $A_{4}$ : $24 \%$, aplicados em função do volume de solo do recipiente.

Foram utilizados sacos de polietileno com capacidade para $3 \mathrm{dm}^{3}$ onde os tratamentos que receberam esterco foram preparados trinta dias antes da semeadura, quando a dose foi adicionada ao solo e incorporada por todo o recipiente. As quantidades de esterco foram aplicadas com base na capacidade volumétrica de solo de cada saco de polietileno. A análise físicoquímica do esterco e solo estão demonstradas na Tabela 1.

Para a semeadura utilizou-se sementes de três variedades de feijão - fava, provenientes de cidades próximas em feiras livres. Sendo elas $V_{1}=$ Lavandeira (Sapé-PB); $V_{2}=$ Raio-de-sol (Sapé$\mathrm{PB}$ ) e $\mathrm{V}_{3}=$ Rajada (Picuí-PB) alocando-se três sementes por recipiente. Após quinze dias da semeadura foi realizado o desbaste deixando-se apenas uma planta por recipiente. Após o desbaste, foi adicionado a superfície do solo de cada recipiente uma cobertura morta composta por uma camada de palhada advinda da vegetação espontânea a fim de manter a umidade do solo, equivalente a $0,1 \mathrm{dm}^{3}$ em todos os vasos. 
Tabela 1. Características físico-químicas dos componentes do solo e esterco usados no cultivo do feijoeirofava. UFPB, Areia-PB.

\begin{tabular}{|c|c|c|c|c|c|c|c|c|c|c|c|c|}
\hline & \multicolumn{12}{|c|}{ Características Químicas } \\
\hline & $\mathrm{pH}$ & C.E & $P$ & $\mathrm{~K}^{+}$ & $\mathrm{Na}^{+}$ & $\begin{array}{c}\mathrm{Ca}^{+} \\
2\end{array}$ & $\mathrm{Mg}^{+2}$ & $\mathrm{Al}^{+3}$ & $\mathrm{H}+\mathrm{Al}$ & SB & $(T)$ & $\mathrm{MO}$ \\
\hline & $\begin{array}{c}\mathrm{H}_{2} \mathrm{O} \\
1: 2,5\end{array}$ & $\begin{array}{c}\mathrm{dS} \mathrm{m}^{-1} \\
1: 5 \\
\end{array}$ & $\begin{array}{c}\mathrm{mg} \\
\mathrm{dm}^{3}\end{array}$ & \multicolumn{6}{|c|}{ 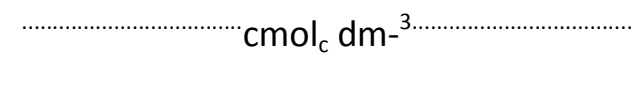 } & \multicolumn{2}{|c|}{$\mathrm{cmol}_{\mathrm{c}} \mathrm{dm}^{-3}$} & $\mathrm{~g} \mathrm{~kg}^{-1}$ \\
\hline Solo & 6,50 & 0,32 & $\begin{array}{c}563 \\
66\end{array}$ & 0,36 & 0,07 & 1,20 & 0,71 & 0,00 & 0,81 & 2,34 & $\begin{array}{c}3,1 \\
5\end{array}$ & 4,79 \\
\hline \multirow[t]{3}{*}{ Esterco } & 7,82 & 1,00 & 29,0 & 1,56 & 1,68 & 4,2 & - & 0,00 & 0,00 & 7,16 & $\begin{array}{c}7,1 \\
6\end{array}$ & 4,50 \\
\hline & \multicolumn{12}{|c|}{ Características Físicas } \\
\hline & Areia & Silte & & Argila & & $\begin{array}{l}\text { nsidad } \\
\text { barente }\end{array}$ & $\begin{array}{l}\text { e } D \\
\mathrm{~g} \mathrm{~cm}^{-3}\end{array}$ & Sensidad & e Real & $\begin{array}{r}\text { Poro } \\
\text { Tc } \\
\text { m }\end{array}$ & $\begin{array}{l}\text { dade } \\
\text { al } \\
\mathrm{n}^{3}\end{array}$ & $\begin{array}{l}\text { Classe } \\
\text { Textural }\end{array}$ \\
\hline Solo & 851 & 99 & & 50 & & 1,64 & & 3,10 & & & & $\begin{array}{l}\text { Areia } \\
\text { Franca }\end{array}$ \\
\hline
\end{tabular}

$\mathrm{SB}=$ soma de bases; $\mathrm{CE}=$ condutividade elétrica; $\mathrm{T}$ = capacidade de troca de cátions total; $\mathrm{M} . \mathrm{O}=$ matéria orgânica.

O preparo da solução salina consistiu no acréscimo de cloreto de sódio à água do sistema de abastecimento local (CAGEPA), sendo a quantidade estipulada pela equação 1 conforme Rhoades et al. (2000). A solução salina só foi aplicada a partir dos 15 dias após a semeadura visando uma melhor taxa de germinação e uniformidade das plantas.

$$
\text { Equação 1: } Q=\text { CEa } \times 640
$$

Sendo: $\mathrm{Q}=$ Quantidade de $\mathrm{NaCl}\left(\mathrm{mg} \mathrm{L}^{-1}\right)$ e $\mathrm{CEa}=$ Representa o valor desejado da condutividade

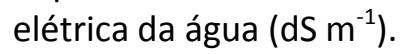

A necessidade de água diária aplicada (Etc) foi feita com base na evapotranspiração de referência $\left(E t_{0}\right)$, em milímetros, calculada pelo método FAO56 de Pennman-Monteith (ALLEN et al., 1998) a partir de dados obtidos da estação meteorológica de São Gonçalo-PB e na evapotranspiração da cultura $(\mathrm{Kc})$ para cada fase do seu ciclo fenológico determinada por Simeão et al. (2013). O Kc na fase inicial da cultura (20 dias após a emergência) foi de 0,87 . Na segunda fase (21 aos 40 DAE) 1,52 resultando em um consumo diário de 0,09 L por planta na primeira fase e $0,16 \mathrm{~L}$ na segunda.

Foram aferidas as seguintes variáveis 47 dias após a semeadura:

Comprimento do ramo principal $(\mathrm{cm})$ : sendo realizado desde o nível do solo até o ápice da haste através de uma régua graduada;

Diâmetro do ramo principal $(\mathrm{mm})$ : mensurado através de um paquímetro digital a um centímetro de altura em relação ao solo;

Número de folhas: realizando-se a contagem de folhas que apresentavam limbo foliar completamente desenvolvido.

Os dados referentes às variáveis mensuradas foram submetidos ao teste de $\mathrm{F}$ a 0,05\% de significância, por meio de análise de variância, quando significativas as médias das variáveis foram submetidas aos testes de comparação de média para as cultivares e regressão para os níveis salinos e doses de adubo. As análises estatísticas foram realizadas no software SISVAR Versão 5.6 (FERREIRA, 2014).

\section{Resultados e Discussão}

Observa-se que houve efeito interativo para variedades $x$ salinidade da água $x$ adubação no crescimento vegetativo do feijão-fava, demonstrando que ambos os fatores interferem simultaneamente nessa cultura. Alguns autores observaram efeitos interativos entre estes fatores em diversas espécies como Cucumis melo (PEREIRA et al., 2017; LOPES et al.; 2017), Cucurbita sp (SANTOS et al., 2018), Carica papaya (LIMA NETO et al., 2016) e Phaseolus Lunatus (NASCIMENTO et al., 2017). 
Tabela 2. Resumo da análise de variância da comprimento do ramo (CR), diâmetro do caule (DC) e número de folhas (NF) aos 47 DAS de três variedades de feijão-fava $\left(V_{1}\right.$ : lavandeira; $V_{2}$ : raio-de-sol e $V_{3}$ : rajada), adubadas com quatro volumes de esterco bovino e submetidas a cinco níveis salinos da água de irrigação, UFCG, Pombal, 2018.

\begin{tabular}{|c|c|c|c|c|}
\hline \multirow[b]{2}{*}{$\begin{array}{l}\text { Fonte de } \\
\text { variação }\end{array}$} & \multirow[b]{2}{*}{ GL } & \multicolumn{3}{|c|}{ Quadrado médio } \\
\hline & & $\mathrm{CR}(\mathrm{cm})$ & $\mathrm{DC}(\mathrm{mm})$ & NF \\
\hline Salinidade (S) & 4 & $44,32 * *$ & $2,70^{* *}$ & $231,91 * *$ \\
\hline Adubação (A) & 3 & $186,72^{* *}$ & $19,12^{* *}$ & $245,68^{* *}$ \\
\hline Variedade (V) & 2 & $195,69 * *$ & $6,50 * *$ & $84,19 * *$ \\
\hline$V \times A$ & 6 & $33,95^{* *}$ & $1,59 * *$ & $101,80 * *$ \\
\hline$V \times S$ & 8 & $12,53 * *$ & $3,16^{* *}$ & $40,23 * *$ \\
\hline$S \times A$ & 12 & $6,77^{* *}$ & $1,57^{* *}$ & $9,80 * *$ \\
\hline $\mathrm{V} \times \mathrm{A} \times \mathrm{S}$ & 24 & $12,10 * *$ & $0,83^{* *}$ & $48,43^{* *}$ \\
\hline Bloco & 3 & $2,13^{* *}$ & $0,04^{* *}$ & $0,34^{* *}$ \\
\hline Resíduo & 177 & 0,69 & 0,03 & 1,15 \\
\hline Total & 239 & & & \\
\hline CV (\%) & & 5,33 & 5,10 & 6,04 \\
\hline Média geral & & 15,59 & 3,69 & 17,77 \\
\hline
\end{tabular}

${ }^{\text {ns }}$ não significativo, ${ }^{* *}$ significativo a $1 \%$ de probabilidade; *significativo a $5 \%$ de probabilidade pelo teste $\mathrm{F} ; \mathrm{CV}$ (coeficiente de variação); GL (Grau de liberdade).

No que se refere ao comprimento do ramo (Figura 1) verificou-se que a variedade Raio-desol $\left(V_{2}\right)$, apresentou maior comprimento se comparado às variedades Lavandeira $\left(V_{1}\right)$ e a Rajada $\left(V_{3}\right)$. Este comportamento pode está relacionado à capacidade genética da variedade de se desenvolver ou pela tolerância a salinidade, o que torna uma opção viável de cultivo, uma vez que o semiárido paraibano apresenta solos excessivamente salinos (PASSOS et al., 2010; ARANTES et al., 2016). A diversidade constatada entre cultivares também foi observada por Nascimento et al. (2017) ao estudarem quatro cultivares de feijão-fava (Branca, Orelha de Vó, Rosinha e Roxinha), onde observaram que a cultivar Roxinha foi mais tolerante à salinidade. 
Figura 1. Comprimento do ramo aos 47 DAS de três variedades de feijão-fava $\left(V_{1}\right.$ : lavandeira; $V_{2}$ : raio-de-sol e $V_{3}$ : rajada), adubadas com quatro volumes de esterco bovino e submetidas a cinco níveis salinos da água de irrigação, UFCG, Pombal, 2018.
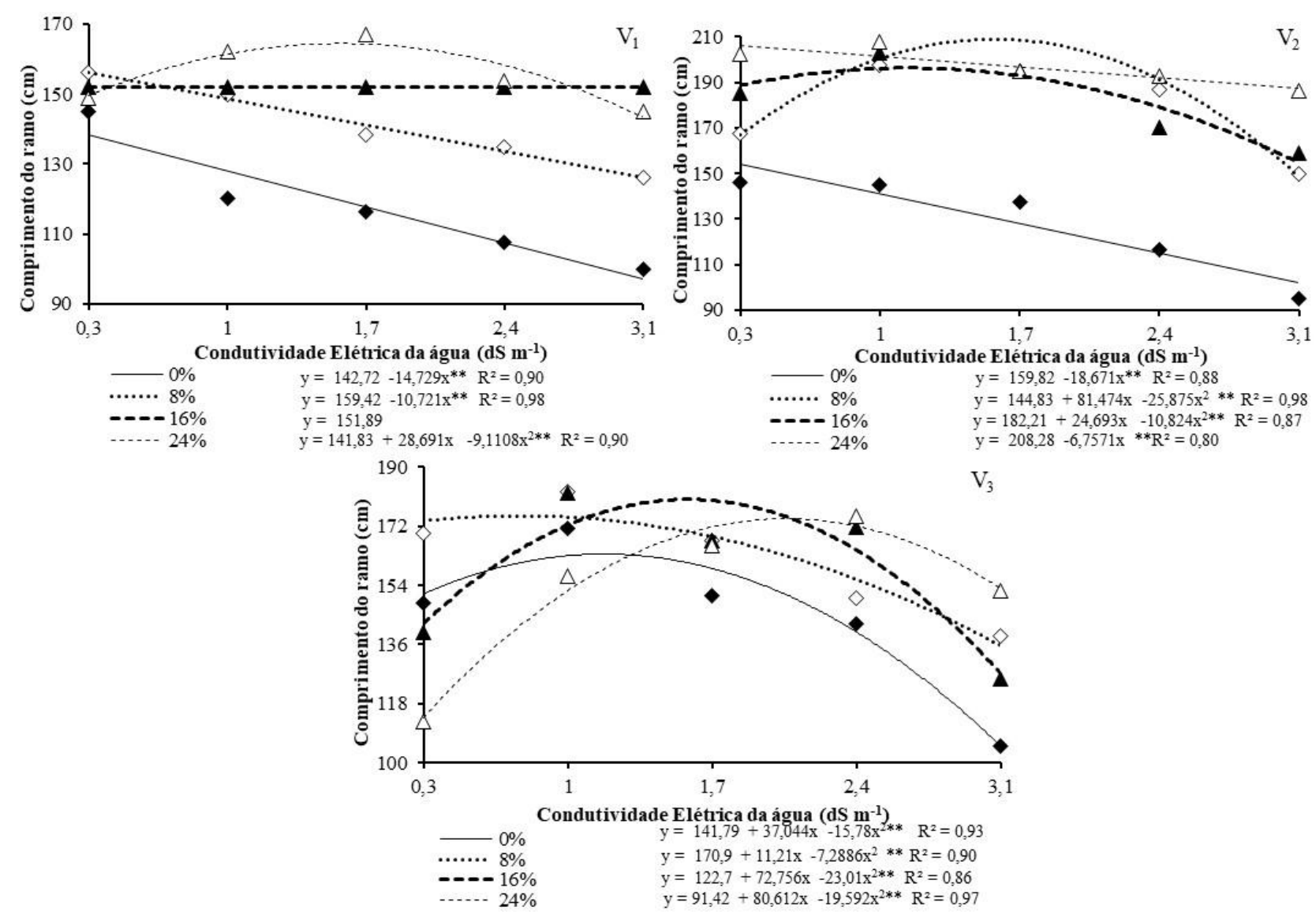

$\mathrm{Na}$ variedade $\mathrm{V}_{1}$ observou-se que a dose de adubo orgânico a 24\%, em função da condutividade elétrica da água de irrigação, apresentou comportamento quadrático com máximo estimado de $164,41 \mathrm{~cm}$, na condutividade de $1,6 \mathrm{dm}^{-1}$. Enquanto que as doses de 0 e $8 \%$ demonstraram comportamento linear decrescente com redução de 30 e 19,39\% entre os níveis salinos de 0,3 e $3,1 \mathrm{dm}^{-1}$, atingindo mínimo estimados de 97,06 e $126,18 \mathrm{~cm}$, respectivamente. A dose de $16 \%$ não apresentou significância, no entanto apresentou média de $151,89 \mathrm{~cm}$.

O uso de insumos orgânicos, dentre eles o esterco bovino incrementa as características físico-químicas do solo, devido elevar a matéria orgânica, disponibilidade de nutrientes, retenção de umidade e capacidade de troca de cátions (RODRIGUES et al., 2017; NUNES et al., 2018). Toledo et al. (2017) ao avaliarem a resposta do feijoeiro submetido a aplicação de fertilizantes de natureza orgânica e mineral concluíram que o esterco proporcionou maior crescimento e produtividade.
Em situações de plantas irrigadas com águas salinas, esses insumos orgânicos proporcionam maiores ajustes osmóticos entre as raízes e a solução do solo, minimizando a drasticidade dos efeitos tóxicos dos sais sobre o crescimento das plantas (MEDEIROS et al., 2016; SOUZA et al., 2018), como constatado nas plantas submetidas às doses de 16 e $24 \%$ de esterco bovino, avaliados neste experimento.

Para o comprimento do ramo na variedade $V_{2}$ as doses de $8 \%$ e $16 \%$ apresentaram aumento gradual em função da condutividade elétrica da água de irrigação com máximo de 208,94 e $196,27 \mathrm{~cm}$, nas salinidades de 1,6 e $1,1 \mathrm{dm}^{-1}$ respectivamente, apresentando posteriormente redução de 28,8 e $21,16 \%$ quando cultivado com água de $3,1 \mathrm{dm}^{-1}$. As doses de $0 \%$ e $24 \%$ apresentaram comportamento linear decrescente com redução de 33,8 e 9,17\% entre o maior e o menor nível salino avaliado. Enquanto que, na variedade $V_{3}$ constatou-se para o comprimento do ramo que todas as doses de adubo orgânico $(0,8,16$ e 24\%) apresentaram comportamento quadrático com máximos 
estimados de 163,51, 175,17, 180,2 e $174,3 \mathrm{~cm}$ na condutividade de $1,2,0,7,1,6$ e $2,1 \mathrm{dm}^{-1}$, respectivamente.

A redução observada quando a fava foi cultivada na salinidade máxima da água de irrigação, independentemente das doses de adubo orgânico, pode se justificar segundo Pereira et al. (2017) ao excesso de sais ocasionar efeitos tóxicos devido ao acúmulo de íons, onde essa toxicidade de íons, durante o processo de germinação e desenvolvimento da planta, causa diversos distúrbios fisiológicos e bioquímicos, como o desequilíbrio hormonal e a redução do uso de reservas.
Os dados do diâmetro do caule das diferentes variedades de feijão-fava em função dos tratamentos avaliados demonstrou valores razoavelmente superiores na variedade $V_{2}$ se comparado às demais variedades (Figura 2). Segundo Silva et al. (2015) ao estudarem a divergência genética entre acessos de feijoeiro fava verificaram que há variabilidade genética sendo o cultivar Raio de Sol com destaque no comportamento vegetativo.

Figura 2. Diâmetro do caule aos 47 DAS de três variedades de feijão-fava $\left(V_{1}\right.$ : lavandeira; $V_{2}$ : raio-de-sol e $V_{3}$ : rajada), adubadas com quatro volumes de esterco bovino e submetidas a cinco níveis salinos da água de irrigação, UFCG, Pombal, 2018.
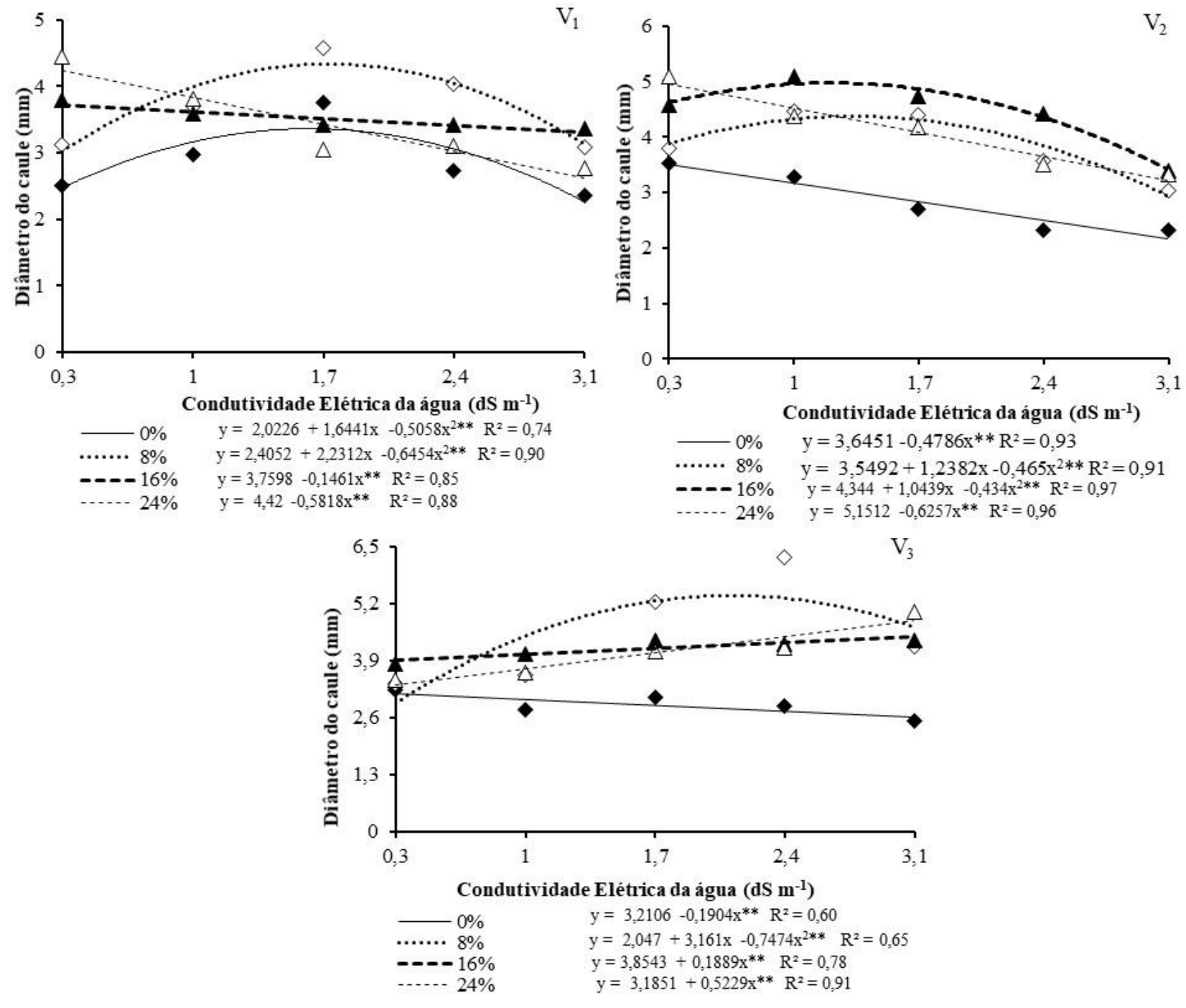

$\mathrm{Na}$ variedade $\mathrm{V}_{1}$, observou-se que as doses 0 e $8 \%$ apresentaram comportamento quadrático atingindo máximo estimado de 3,35 e 4,33 mm nas condutividades de 1,6 e 1,7 $\mathrm{dm}^{-1}$, respectivamente, enquanto que as dose de $16 \mathrm{e}$
24\% de adubo orgânico exerceu comportamento linear decrescente com redução de 11,05 e $38,44 \%$ respectivamente, entre o menor e maior nível salino estudado. 
O excesso de sais tanto do insumo orgânico em maiores quantidades, quanto da água salina usada na irrigação pode ter inibido o crescimento caulinar, assim como Sousa et al. (2018) observaram em mudas de cajueiro irrigadas com água salina nas maiores concentrações de esterco. De acordo com Santana et al. (2018) às maiores salinidades da água de irrigação resultam em menores consumos de água pelas plantas de feijoeiro, reduzindo crescimento.

$\mathrm{Na}$ variedade $\mathrm{V}_{2}$ constatou-se para as doses de 8 e $16 \%$ seguiu efeito quadrático em função do aumento de sais na água de irrigação com máximo estimado de 4,37 e $4,97 \mathrm{~mm}$ nas condutividades de 1,3 e $1,2 \mathrm{dm}^{-1}$. No entanto, nas doses de 0 e $24 \%$ observa-se que houve efeito linear decrescente com redução de 38,28 e $35,28 \%$ atingindo mínimo estimado de 2,16 e 3,21 na condutividade de $3,1 \mathrm{dm}^{-1}$.

Tanto a falta, quanto o excesso de esterco bovino interfere negativamente no crescimento do feijoeiro fava, sendo na $V_{2}$ a concentração de $16 \%$ a melhor, pois concentra maior diâmetro. Visto que, o cultivo do feijão-fava é realizado pelos agricultores familiares com manejo mínimo, sendo na maioria das vezes usado insumo orgânico na adubação (CARMO et al., 2013).

Nos resultados de diâmetro do caule para a variedade $V_{3}$, verificou-se que a dose de $8 \%$ apresentou comportamento quadrático com máximo estimado de $5,38 \mathrm{~mm}$ aos $2,1 \mathrm{dm}^{-1}$, enquanto que a dose de $0 \%$ demonstrou efeito linear decrescente com redução de $16,82 \%$ na condutividade elétrica de $3,1 \mathrm{dm}^{-1}$. Comportamento inversamente proporcional foi verificado para os tratamentos com as doses 16 e 24\%, o qual apresentaram comportamento linear crescente com aumento de 11,73 e $30,41 \%$, respectivamente, em função do aumento da adição de sais na água de irrigação.

Esse acréscimo mesmo em condições salinas se deve ao esterco bovino aplicado no substrato formar uma camada de impedimento às perdas elevadas de água por evaporação, o que possibilita às células vegetais permanecerem túrgidas por mais tempo em relação às plantas que não receberam o insumo ou receberam em menor quantidade (SILVA et al., 2013).

Em relação ao número de folhas das plantas de feijão-fava observou-se variação deste parâmetro entre as variedades em função das doses de adubo orgânico e da condutividade elétrica da água de irrigação.

$\mathrm{Na}$ Figura 3, referente ao número de folhas da variedade $V_{1}$, constatou-se aumento gradativo, atingindo valores máximos estimados de 20,39 e 21,26 folhas por planta na condutividade 1,5 e $0,9 \mathrm{dm}^{-1}$ para as doses 0 e $8 \%$ de adubo orgânico, respectivamente, reduzindo drasticamente com a contínua adição de sais. Esse comportamento demonstra que é possível produzir feijão-fava sob condições de estresse, no entanto, o excesso de sais é prejudicial ao cultivo da cultura. A dose de $16 \%$ de adubo orgânico não se mostrou eficiente como atenuador dos efeitos deletérios causados pelos níveis salinos devido ter reduzido $13,81 \%$ o número de folhas em função do aumento na condutividade elétrica da água de irrigação. A dose de $24 \%$ de adubo não apresentou efeito significativo nos tratamentos avaliados, porém apresentou média de 16,59 folhas por planta. 
Figura 3. Número de folhas aos 47 DAS de três variedades de feijão-fava $\left(V_{1}\right.$ : lavandeira; $V_{2}$ : raio-de-sol e $V_{3}$ : rajada), adubadas com quatro volumes de esterco bovino e submetidas a cinco níveis salinos da água de irrigação, UFCG, Pombal, 2018.
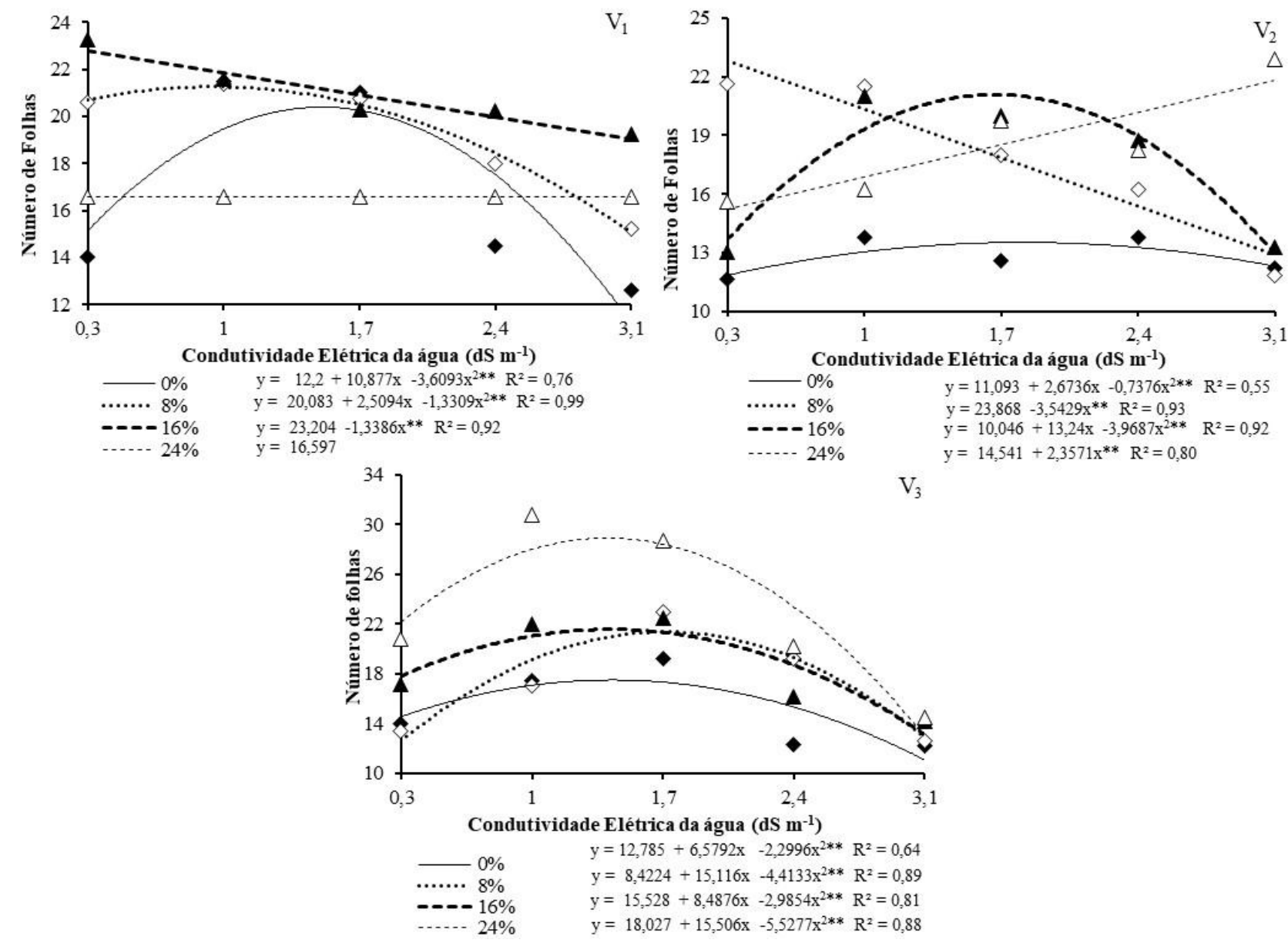

O uso em excesso de esterco pode aumentar os níveis de nitrogênio e levar à salinização do solo e ao aumento da condutividade elétrica, o que causa desequilíbrio nutricional da planta e prejudica seu desenvolvimento (ALVES et al. 2008). Segundo Taiz et al. (2017) quando a pressão osmótica aumenta, devido a uma maior concentração de sal no solo, a planta reduz a absorção de água do mesmo, minimizando a absorção excessiva de sais nocivos como $\mathrm{Na}^{+}$e $\mathrm{Cl}^{-}$.

Analisando o número de folhas da variedade $V_{2}$, verificou-se comportamentos distintos entre as doses de adubo avaliado, o qual as doses de 0 e $16 \%$ apresentaram simultaneamente comportamentos quadráticos com máximos estimados de 13,51 e 21,08 folhas por planta, nas condutividade de 1,8 e $1,7 \mathrm{dm}^{-1}$, respectivamente. A dose de $24 \%$ apresentou comportamento linear crescente com aumento de $30,21 \%$ entre a condutividade de 0,3 e $3,1 \mathrm{dm}^{-}$ 1 , no entanto a dose de $8 \%$ adubo foi a mais afetada pelo incremento de sais na água de irrigação com redução de $43,5 \%$ de folhas por planta. Alves et al. (2008) ao avaliarem comportamento do feijoeiro fava na cultivar Raio de Sol sob adubação organomineral, constataram que uso do esterco bovino incrementa crescimento vegetativo e produtividade da cultura sendo uma alternativa viável.

$A$ variedade $V_{3}, \quad$ apresentou comportamento similar em todas as doses de adubo orgânico avaliados em função dos níveis de condutividade elétrica da água de irrigação, portanto verificou-se pontos de máximo de $17,48,21,36,21,55$ e 28,9 de número de folhas entre as condutividades de 1,4 , e $1,7 \mathrm{dm}^{-1}$. Observou-se ainda, que o aumento de sais causou redução drástica no número de folhas, o que consequentemente compromete a taxa fotossintética das plantas, bem como o crescimento e o desenvolvimento do feijão-fava.

A emissão foliar do feijão-fava acresceu até às condutividades de 1,4 e 1,7 $\mathrm{dS} \mathrm{m}^{-1}$, com maiores valores com uso do esterco bovino se comparado ao tratamento testemunha (ausente do insumo) nesta variedade, tal fato explicado 
pelo efeito benéfico deste insumo minimizando o efeito deletério em condições salinas (FONSECA et al., 2016).

\section{Conclusões}

A variedade Raio de Sol apresenta maior crescimento em relação a Rajada e Lavandeira, entretanto a cultivar Rajada apresentou maior aclimatização às condições salinas principalmente com uso do esterco bovino na concentração de $24 \%$.

O esterco bovino atenua o efeito nocivo da salinidade, entretanto, doses acima de $16 \%$ de esterco em altas salinidades podem ser prejudiciais ao feijoeiro-fava.

\section{Referências}

ALLEN, R.G.; PEREIRA, L.S.; RAES, D.; SMITH, M. Crop evapotranspiration: guidelines for computing crop water requirements. Rome: FAO, 1998. 300p. (FAO. Irrigation and drainage paper, 56).

ALVARES, C.A.; STAPE, J.L.; SENTELHAS, P.C.; GONÇALVES, J.L.M.; SPAROVEK, G. Köppen's climate classification map for Brazil. Meteorologische Zeitschrift, v. 22, p. 711-728, $2013 . \quad$ https://doi.org/10.1127/09412948/2013/0507

ALVES, A.U.; OLIVEIRA, A.P.; ALVES, A.U.; DORNELAS, C.S.M.; ALVES, E.U.; CARDOSO, E.A.; OLIVEIRA, A.N.P.; CRUZ, I.S. Lima beans production and economic revenue as function of organic and mineral fertilization. Horticultura Brasileira, v.26, n.2, p.251-254, 2008. http://dx.doi.org/10.1590/S0102$\underline{05362008000200024}$

ARANTES, A.M.; DONATO, S.L.R.; SIQUEIRA, D.L.; COELHO, E.F.; SILVA, T.S. Gas exchange in different varieties of banana prata in semi-arid environment. Revista Brasileira de Fruticultura, v.38, n.2, p.1-12, 2016. http://dx.doi.org/10.1590/0100-29452016600

CARMO, M.D.S.; CARVALHO, E.M.S.; GOMES, R.L.F.; LOPES, A.C.A.; CAVALCANTE, G.R.S. Avaliação de acessos de feijão-fava, para resistência a Colletotrichum truncatum, em condições de folhas destacadas e campo. Summa Phytopathologica, v.41, n.4, p.292-297, 2015. https://dx.doi.org/10.1590/0100-5405/2079
CARMO, M.D.S.; GOMES, R.L.F.; LOPES, A.C.A.; PENHA, J.S.; GOMES, S.O.; ASSUNÇÃO FILHO, J.R. Genetic variability in subsamples of determinate growth lima bean. Crop Breeding and Applied Biotechnology, v.13, n.3, p. 158-164, 2013. http://dx.doi.org/10.1590/S1984$\underline{70332013000300002}$

DINIZ, G.L.; SALES, G.N.; SOUSA, V.F.O.; ANDRADE, F.H.A.; SILVA, S.S.; NOBRE, R.G. Produção de mudas de mamoeiro sob salinidade da água de irrigação e adubação fosfatada. Revista de Ciências Agrárias, v.41, n.1, p. 218228, 2018. http://dx.doi.org/10.19084/RCA17067

FERREIRA, D. F. Sisvar: A Guide for Its Bootstrap Procedures in Multiple Comparisons. Ciência e Agrotecnologia, v.38, n.2, p.109-112, 2014.

FONSECA, V.A.; BRITO, C.F.B.; BEBÉ, F.V.; ARANTES, A.M.; SANTOS, L.G. Feijão-Caupi Irrigado com Água Salina e Adubado com Esterco Bovino. Engenharia na Agricultura, v.24, n.5, p.427-438, 2016.

IBGE. Produção agrícola municipal. Área plantada, área colhida, quantidade produzida, rendimento médio e valor das lavouras temporárias: fava em grão, 2016. Disponivel em: https://sidra.ibge.gov.br/pesquisa/pam/tabelas. Acesso em: 04 agosto 2018.

LOPES, M.A.C.; MUNIZ, R.V.S.; ALVES, S.S.V.; FERREIRA, A.C.; SÁ, F.V.S.; SILVA, L.A. Água salina e substratos no crescimento inicial do meloeiro. Irriga, v.22, n.3, p.469-484, 2017. https://doi.org/10.15809/irriga.2017v22n3p469$\underline{484}$

MEDEIROS, S.A.S.; CAVALCANTE, L.F.; BEZERRA, M.A.F.; NASCIMENTO, A.M.; BEZERRA, F.T.C.; PRAZERES, S.S. Água Salina e Biofertilizante de Esterco Bovino na Formação e Qualidade de Mudas de Maracujazeiro Amarelo. Irriga, v. 21, n.4, p.779-795, 2016. https://doi.org/10.15809/irriga.2016v21n4p779$\underline{795}$

NASCIMENTO, J.A.M.; CAVALCANTE, L.F.; CAVALCANTE, I.H.L.; PEREIRA, W.E.; DANTAS, S.A.G.; MEDEIROS, S.A.S. The impacts of biofertilizer and mineral fertilization on the growth and production of yellow passion fruit irrigated with moderately saline water. Ciencia e 
Investigación Agraria, v.43, n.2, p.253-262, 2016. https://dx.doi.org/10.4067/S0718$\underline{16202016000200008}$

NASCIMENTO, M.G.R.; ALVES, E.U.; SILVA, M.L.M.; RODRIGUES, C.M. Lima bean (Phaseolus lunatus L.) Seeds exposed to different salt concentrations and temperatures. Revista Caatinga, v.30, n.3, p.738-747, 2017. https://dx.doi.org/10.1590/198321252017v30n322rc.

NUNES, J.A.S.; NUNES, J.C.; SILVA, J.A.; OLIVEIRA, A.P.; CAVALCANTE, L.F.; ORESCA, D.; SILVA, O.P.R. Influence of spacing and application of biofertilizer on growth and yield of okra (Abelmoschus esculentus (L.) Moench). African Journal of Biotechnology, v. 17, p. 17-23, 2018. https://doi.org/10.5897/AJB2017.16277

NUNES, J.C.; CAVALCANTE, L.F.; PEREIRA, W.E.; SOUZA, J.T.A.; ALMEIDA, D.J.; ORESCA, D.; FERNANDES, P.D. Gas exchange and productivity of yellow passion fruit irrigated with saline water and fertilized with potassium and biofertilizer. Ciência e Investigación Agraria, v.44, n.2, p.168183, 2017.

http://dx.doi.org/10.7764/rcia.v44i2.1742

PASSOS, A.R.; SILVA, S.A.; SOUZA, C.S.; SOUZA, C.M.M.; FERNANDES, L.S. Parâmetros genéticos de caracteres agronômicos em genótipos de mamoneira. Pesquisa Agropecuária Brasileira, v.45, n,7, p.709-714, 2010. http://dx.doi.org/10.1590/S0100$\underline{204 \times 2010000700011}$

PEREIRA, F.A.L.; MEDEIROS, J.F.; GHEYI, H.R.; DIAS, N.S.; PRESTON, W.; VASCONCELOS, C.B.L. Tolerance of melon cultivars to irrigation water salinity. Revista Brasileira de Engenharia Agrícola e Ambiental, v. 21, n.12, p.846-851, 2017. http://dx.doi.org/10.1590/18071929/agriambi.v21n12p846-851.

RHOADES, J. D.; KANDIAH, A.; MASHALI, A. M. Uso de águas salinas para produção agrícola. Campina Grande: UFPB, 2000. 117p.

RODRIGUES, R.M.; CAVALCANTE, L.F.; SOUTO, A.G.L.; GHEY, H. R.; MESQUITA, F.O. Growth and regrowth of neem after cutting in saline - sodic soil treated with orgânics inputs. Revista Caatinga, v.30, p.116-124, 2017. http://dx.doi.org/10.1590/198321252017v30n113rc

SANTANA, M.J.; CARVALHO, J.A.; ANDRADE, M.J.B.; SILVA, E.L. Development of the Bean Plant (Phaseolus Vulgaris L. CV Esal 686) Under Different Irrigation Water Salinity Levels. Irriga, v.8, $\quad$ n.1, p.29-36, 2018. http://dx.doi.org/10.15809/irriga.2003v8n1p29$\underline{36}$

SANTOS, A.S.; SÁ, F.V.S.; SOUTO, L.S.; SILVA, M.K.N.; MOREIRA, R.C.L.; LIMA, G.S.; LIMA, L.A.; MESQUITA, E.F. Tolerance of Varieties and Hybrid of Pumpkin and Squash to Salt Stress. Journal of Agricultural Science, v.10, n.1, p.38-44, 2018. https://doi.org/10.5539/jas.v10n1p38

SILVA, F.L.B.; LACERDA, C.F.; NEVES, A.L.R.; SOUSA, G.G.; SOUSA, C.H.C.; FERREIRA, F.J. Irrigação com Águas Salinas e Uso de Biofertilizante Bovino nas Trocas Gasosas e Produtividade de Feijão-de-Corda. Irriga, v. 18, n.2, p.304-317, 2013. https://doi.org/10.15809/irriga.2013v18n2p304

SILVA JÚNIOR, E.G.; SILVA, A.F.; LIMA, J.S.; SILVA, M.F.C.; MAIA, J.M. Vegetative development and content of calcium, potassium, and sodium in watermelon under salinity stress on organic substrates. Pesquisa Agropecuária Brasileira, v.52, n.12, p.1149-1157, 2017. http://dx.doi.org/10.1590/s0100-

$\underline{204 \times 2017001200003}$

SILVA, V.B.; GOMES, R.L.F.; LOPES, A.C.A.; DIAS, C.T.S.; SILVA, R.N.O. Genetic diversity and promising crosses indication in lima bean (Phaseolus lunatus) accessions. Semina: Ciências Agrárias, v.36, n.2, p. 683-692, 2015. http://dx.doi.org/10.5433/1679-

$\underline{0359.2015 v 36 n 2 p 683}$

SIMEÃO, M.; OLIVEIRA, A.E.S.; SANTOS, A.R.B.; MOUSINHO, F.E.P.; Ribeiro, A.A. Determinação de ETc e Kc para o feijão-fava (Phaseolus lunatus L.) na região de Teresina, Piauí. Revista Verde de Agroecologia e Desenvolvimento Sustentável, v.8, n.2, p.219-296, 2013.

SOUSA, V.F.O. Comportamento vegetativo, fisiológico e produtivo na cultura do meloeiro sob salinidade. 2017. 64p. Dissertação (Mestrado em Horticultura Tropical) 
Universidade Federal de Campina Grande, Pombal-PB, 2017.

SOUSA, V.F.O.; SANTOS, G.L. ; RODRIGUES, M.H.B.S. ; PIMENTA, S.F. ; DINIZ, G.L. ; RIBEIRO, M.D.S. ; OLIVEIRA, A.M.F. ; SILVA, R.A. . Production of Cashew Rootstocks Submitted to Organic and Mineral Fertilization. Journal of Agricultural Science, v. 10, p. 392-401, 2018. http://dx.doi.org/10.5539/ jas.v10n4p392

SOUZA, L.P.; SOARES, G.L.; GHEYI, H.R.; NOBRE. R.G.; SOARES, L.A.A. Emergence, Growth, and Production of Colored Cotton Subjected to Salt Stress and Organic Fertilization. Revista Caatinga, v.31, n.3, p.719-729, 2018. http://dx.doi.org/10.1590/1983-

21252018v31n322rc

TAIZ, L.; ZEIGER, E.; MOLLER, I.M.; MURPHY, A. Fisiologia e desenvolvimento vegetal. 6. ed. Porto Alegre: Artmed, 2017.

TOLEDO, W.S.; AGÁPTO, J.P.; ALMEIDA, G.F. Common bean (Phaseolus vulgaris L.) productivity in response to different fertilization strategies. Revista Agro@mbiente On-line, v. 11, n. 4, p. 296-306, 2017. 